\title{
Adenoma velloso hipersecretor de recto. Diagnóstico y tratamiento
}

Palabras clave: Adenoma velloso. Tumores de colon.

Key words: Villous adenoma. Colon tumours.

\section{Sr. Director:}

Hemos leído con interés el caso clínico recientemente publicado por ustedes en febrero del presente año (1), en el que se describe el síndrome de depleción hidrosalina secundario a adenoma velloso. Presentamos un nuevo caso, que junto con el anterior, puede servir para profundizar en esta patología tan infrecuente.

Varón de 78 años, con antecedentes de insuficiencia respiratoria secundaria a embolia pulmonar, en tratamiento con Sintrom y oxigenoterapia domiciliaria. RTU de próstata hace tres años por hiperplasia benigna de próstata. Acude a consulta con cuadro de diarreas acuosas de meses de evolución, de contenido mucoide, sin sangre ni pus en las heces, no asociadas a dolor abdominal ni a ningún otra sintomatología digestiva. Exploración física. Peso: $68 \mathrm{~kg}$. Talla $155 \mathrm{~cm}$. TA: 110/60 mmHg. Pulso : 92x'. Afebril. Buena coloración de piel y mucosas. Auscultación cardiaca normal, ascultación pulmonar con hipoventilación en campos izquierdos. Abdomen blando, depresible, no doloroso a la palpación sin masas ni visceromegalias. Pulsos periféri- 
cos presentes. Tacto rectal normal. Hb: $16,9 \mathrm{~g} / \mathrm{dL}$. Leucocitos 8,4 10E9/L fórmula normal. TP: 79,7\%, INR: 1,4. Glu 105 $\mathrm{mg} / \mathrm{dL}$, p-Urea: 1,26 g/L, p-Creatinina: 1,9 mg/dL, Na: 135 $\mathrm{mEq} / \mathrm{L}, \mathrm{K}: 2,7 \mathrm{mEq} / \mathrm{L}, \mathrm{Cl}: 89 \mathrm{mEq} / \mathrm{L}$. s-CEA: $12,4 \mathrm{ng} / \mathrm{ml}$. Se decidió ingreso en planta para reposición hidroelectrolítica. Durante su estancia en nuestro centro se realizó colonoscopia y ecoendoscopia rectal objetivándose en unión rectosigma una gran formación polipoidea, entre los 10 y los $25 \mathrm{~cm}$ de margen anal, afectando a mucosa y muscular, informándose como adenoma velloso con áreas de displasia moderada, estadio T2N0. Ante estos hallazgos clínicos se programó intervención quirúrgica, realizándose resección anterior de recto con anastomosis mecánica (Fig. 1).

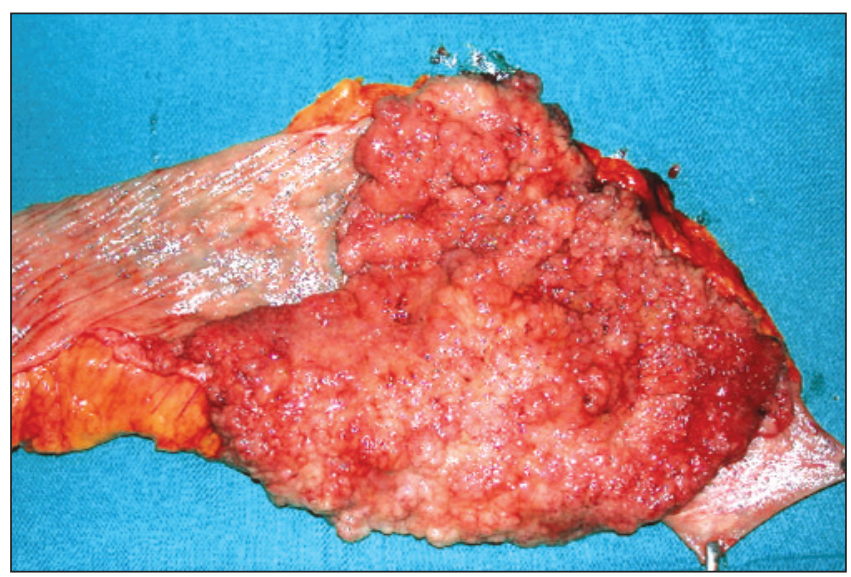

Fig. 1.

El dato más relevante de la existencia de un tumor velloso hipersecretor, es la gran abundancia de moco que segrega en forma de diarrea profusa, así como los trastornos hidroelectrolíticos de él derivados (2). La expulsión de moco por las células prominentes y atípicas del epitelio colónico (hasta $3 \mathrm{~L}$ diarios), puede estar acompañada de pequeñas cantidades de sangre en el momento de la defecación. Si analizamos el contenido de las heces, observamos concentraciones elevadas de $\mathrm{K}$ y $\mathrm{Cl}$. Esta pérdida hidroelectrolítica continua, lleva consigo la activación de mecanismos compensatorios, que si cronifican, llegan a producir fallo prerrenal (3).

En general son tumores grandes y su extensión depende del momento en que sean diagnosticados a lo largo de su evolución, por lo que no es raro encontrar tumores de más de $10 \mathrm{~cm}$. La localización del mismo y su tamaño pueden dar lugar a síndromes dolorosos abdominales de tipo suboclusivo si su localización es alta o a tenesmo rectal si se localizan en recto. La exploración física resulta normal en la mayoría de los casos, únicamente si el tumor asienta en la zona distal del recto puede ser detectado por el tacto, apreciándose una masa blanda de difícil identificación con salida de abundante moco claro en el guante. Es importante buscar zonas más induradas que puedan corresponder a áreas de implantación neoplásica, pues hasta en un $30 \%$ degeneran a adenocarcinoma (4).

El diagnóstico preciso que confirme la sospecha clínica es la endoscopia con toma de biopsias. A diferencia de los adenocarcinomas, los pólipos vellosos ofrecen un aspecto de mucosa conservada sin la sensación de rigidez y fijación de las neoplasias.

El tratamiento inicial de estos pacientes consiste en normalizar la homeostasis del medio interno mediante la reposición hidroelectrolítica. El uso de la indometacina por su acción inhibidora sobre la PGE2, puede estar indicado temporalmente si se consiguen disminuir las pérdidas por heces. Dosis de hasta $400 \mathrm{mg}$ /día se han probado en situacionres severas, sin conseguir disminuir totalmente la sintomatología (5). En cualquier caso, la utilización de este fármaco, debe hacerse con precaución por la posibilidad de exacerbar el fallo renal de estos pacientes. El tratamiento definitivo debe ser la extirpación del tumor, en función de la extensión e implantación del mismo en la pared colónica. Así, si el tumor es poco extenso puede tratarse con extirpación local endoscópica o quirúrgica, resecando la mucosa sobre la que se encuentra implantada (6). Por el contrario, cuando el tumor es grande, como el que nos ocupa, debe realizarse resección intestinal asegurando márgenes libres de enfermedad para evitar recidiva de la misma, más aún si en la biopsia previa existen áreas de displasia o de adenocarcinoma.

V. Valentí, J.L. Hernández-Lizoáin, A. Gil, M. Cervera, C. Pastor, I. Poveda, R. Moncada y J.A. Cienfuegos

Servicio de Cirugía General y del Aparato Digestivo. Clínica Universitaria de Navarra. Pamplona, Navarra

\section{Bibliografía}

1. Corbatón Anchuelo A, López Castañeyra P, Mayol Martínez J, Enríquez González LS, Serrano Ríos M. Síndrome de depleción hidrosalina secundaria a adenoma velloso de recto: mecanismo de secreción. A propósito de un caso. Rev Esp Enferm Dig 2003; 95 (2): 157-60.

2. Mc Kittrick LS, Wheelock FC. Carcinoma of colon. Springfield, Illinois: Charles C Thomas 1954. p. 61.

3. Emrich $\mathrm{J}$, Niemeyer C. The secreting villous adenoma as a rare cause of acute renal failure. Med Klin (Munich) 2002; 97 (10): 619-23.

4. Sobin L. Histopathology of bleeding from polyps and carcinomas of the large intestine. Cancer 1985; 55: 557-81.

5. Huchzermeyer H, Baller D, Nieporte U, Gergs P. Villous rectal adenomas and secretory diarrhea. Z Gastroenterol 1995; 33 (2): 112-6.

6. Srekalowsky WP. Results of endoscopic removal of villous tumors of the colon. Endoscopy 1983; 15: 49-52. 